record of them at altitudes below $3,000 \mathrm{~m}$., with the exception of Sphagnum Franeonii Warnst ${ }^{3}$.

Many species of Utricularia also are found at Nabugabo, among them being Utricularia appendiculata Bruce, $U$. erecta Kam., $U$. exilis Oliv., $U$. exoleta R. Br.; U. Kirkii Stapf, U. obtusa Sw., U. prehensilis E. Mey., $U$. reflexa Oliv., $U$. spiralis Smith, U. stellaris L., U. subulata L., U. Thonningii Schumach. The genus Utricularia does not seem to be so well represented at any other place in the Protectorate, although some of these species have been found at much higher altitudes on the mountains.

Trichopteryx gracillima C. E. Hubbard is another species recorded from the peat logs of Nabugabo but from no other locality in Uganda. Drosera Burkeana Planch. also has been found nowhere else in Uganda, but D. madagascarensis D.C., which is more abundant at Nabugabo, is also more widely spread.

The type specimens of several of the species enumerated above have been collected in recent years at Nabugabo and, therefore, it seems probable that similar deposits of peat at low altitudes are not very common in tropical Africa. No other striking examples of lowland podsols have been noticed in Uganda, nor is it to be expected that they would occur : for nowhere else at low altitudes is there the same combination of a climate with a heavy rainfall and of soils made up of leached sands. Eggeling ${ }^{3}$ has suggested that at low altitudes in Uganda the Sphagnum community develops only where the natural succession is upset and cites other examples where it has occurred in annually burnt Miscanthidium swamps.

Miscanthidium violaceum is dominant in many swamps in the west of Uganda, and scattered plants of Sphagnum, Utricularia and Drosera are often found in association with it. The soil reaction in these swamps is always very acid but the subsoils, when tested by the chemical section of this department with Comber's reagent, have given a bright red colour, showing that the iron had not yet been leached out.

Crocodiles, which are abundant in Lake Victoria, are absent from Lake Nabugabo. The reason has remained a complete mystery. Lake Nabugabo was formed when a sand spit shut off a bay of Lake Victoria, and at the present time it is separated from the larger lake by a stretch of level ground, only three quarters of a mile wide, which could easily be crossed by crocodiles. Yet no crocodiles have been seen in Lake Nabugabo, although the temperature of the water and the supply of fish would seem to be favourable to them.

It is possible that the water of the lake which, near the eastern shore beside Lake Victoria, has a faint peaty smell and is acid in reaction, may be so distasteful to crocodiles that they avoid it. If this is the case, it is an interesting example of the complexity of the ecosystem, in that the character of the soil has controlled the distribution of so large an animal as the crocodile.

Department of Agriculture, Kampala, Uganda.

Oct. 5.

${ }^{1}$ Richards, P. W., NATURE, 148, 129 (1941).

2 Worthington, E. B., "A Report on the Fisheries of Uganda"' (London, 1932), p. 64

s Eggeling, W. J., J. Ecol., 23, 430 (1935).

\section{Value of Molybdenum for Lettuce}

IN the course of work on the minor element constituents of Chilean nitrate, the value of molybdenum in improving the growth and health of lettuces has been apparent. With one part of molybdenum (as sodium molybdate) in ten million parts of nutrient solution the plants are larger, deeper green and appear to be much more resistant to disease. This improvement occurs whether the molybdenum is used alone or in conjunction with one or more other minor elements as strontium, titanium, vanadium, chromium and zinc. Preliminary experiments even suggest that molybdenum can fend off symptoms of boron deficiency for some time in the early stages of growth, but this point needs confirmation.

If molybdenum in such small doses can definitely be shown to render lettuces less susceptible to disease, it may prove to be a valuable asset to commercial growers, whose losses from various causes are very considerable.

Botanical Department,

W. E. BRENCHLEY.

K. WARINGTON.

Rothamsted Experimental Station, Harpenden, Herts.

Jan. 26.

\section{Sociological Research in Race Relations}

IN the light of some present sociological research in the subject of race relations in Great Britain, may I be allowed briefly to endorse the general arguments advanced by Mrs. Neville-Rolfe in her article on "Biology as a Social Science"1, and more particularly her paragraph on social biology in education ?

So far as my present observations show, popular information in respect to problems of human heredity and human biology in general has barely advanced out of the stage of superstition in many aspects, and much confusion exists over the meaning of various terms of technical or semi-technical usage. Perhaps the most common confusion is in respect to the connotation of the word 'race'. This term is used and accepted quite freely as a 'synonym for 'nation', 'people', or any other similar concept for which an alternative noun cannot readily be found. There appears to be also a fairly wide and quite unanalysed acceptance of such conceptions as 'national psycho. $\log y^{\prime}$, etc., the logical implications of which are that an individual's cultural or social behaviour is 'inherited' much in the same manner as the colour of his skin. Further mysticisms surround the biological and social implications of the phenomenon of racial miscegenation, and that 'blood' itself fulfils the function less romantically ascribed to the genes is as usual an explanation of heredity as the existence of 'criminal types' and the 'science of bumps' !

The 'etiology' of this core of popular 'knowledge' need not be discussed here. The situation, however, plainly suggests that there has been something seriously amiss in previous educational policy. The moral would appear equally plain. Without a foundation of up-to-date information on such subjects it is not easy to see how the average citizen can face with any clarity the many complex problems that are involved in modern social and political policy.

Thorneycreek Cage, K. L. LITTLE. Herschel Road,

Cambridge.

Jan. 31 .

'NATURE, 149, 90 (1942). 